\title{
Kardiyopulmoner Resüsitasyon Eğitiminde Kullanılan İki Farklı Değerlendirme Yönteminin Öğrenme Sürecine Etkisinin İncelenmesi
}

\author{
Selda Karaveli Çakır®, Filiz Özel®, Esra Demirarslan®
}

Kastamonu Üniversitesi, Hemşirelik Bölümü, Kastamonu, Türkiye

Selda Karaveli Çakır, Dr. Öğr. Üyesi Filiz Özel, Dr. Öğr. Üyesi

Esra Demirarslan, Öğr. Gör.
Illetişim:

Dr. Öğr. Üyesi Selda Karaveli Çakır Kastamonu Üniversitesi, Hemşirelik Bölümü, Kastamonu, Türkiye Tel: +903662804103

E-Posta: seldakaraveli@gmail.com
Gönderilme Tarihi : 160cak 2018

Revizyon Tarihi : : 05 Mayıs 2018

Kabul Tarihi : : 06 Mayıs 2018
ÖZET

Amaç: Bu çalışma, kardiyopulmoner resüsitasyon (CPR) eğitiminde kullanılan iki farklı değerlendirme yönteminin öğrenme sürecine etkisinin incelemesi amacıyla yapıımışıır.

Gereç ve Yöntem: Yarı-deneysel olarak gerçekleştirilen bu çalışma, 2014-2015 akademik yilında bir üniversitenin hemşirelik bölümünde ilk yardım dersi alan ve çalış̧maya katılımayı kabul eden öğrencilerle gerçekleștirilmiştir $(n=70)$. Çalışmanın verileri Sosyo-Demografik Özellikler Soru Formu ve CPR Beceri Değerlendirme Formu kullanılarak toplanmıştır. Çalışmaya katıllan öğrenciler öncelikle iki gruba ayrııış ve her iki gruptaki öğrencilere ilk yardım eğitimi verilmiștir. Eğitim sonrasında öğrenciler beceri laboratuvarına alınarak, CPR uygulaması yaptırımıştı. Grup I $(\mathrm{n}=35)$ öğrencilerinin CPR uygulamaları video kayıt yöntemi ile kayıt edilmiş ve daha sonra her öğrenciye kendi video kaydı izlettirilerek, kendilerini öz değerlendirme yöntemi ile değerlendirmeleri sağlanmış ve ilk uygulama puanı elde edilmiştir. İkinci aşamada, video kaydını izleyen öğrencilere CPR uygulaması tekrarlatılarak, eğitmen tarafından değerlendirilmiş ve ikinci uygulama puanı elde edilmiştir. Grup II $(n=35)$ öğrencilerinin CPR uygulamaları tek bir eğitmen tarafından geribildirim yöntemi ile değerlendirilmiş ve ilk uygulama puanları elde edilmiştir. İkinci aşamada, öğrencilere CPR uygulaması tekrarlatılarak ikinci uygulama puanları elde edilmiştir. Veriler SPSS programı ile değerlendirilmiştir.

Bulgular: Çalışmaya dahil edilen öğrencilerin yaş ortalamasııın $20.82 \pm 1.28, \% 82.9^{\prime}$ unun kadın ve $\% 90^{\prime}$ ’ının düz liseden mezun olduğu saptanmıştır. Çalışmanın sonucunda her iki grupta da ilk ve ikinci uygulama puanları arasında istatistiksel olarak anlamlı fark olduğu bulunmuştur $(p<0.05)$. CPR öğrenme sürecinde geribildirim yöntemi ile öz değerlendirme yöntemi arasında fark olmadığı saptanmıştır.

Sonuç: CPR becerisinin öğrenilmesi açııından iki farklı eğitim yöntemi arasında fark bulunmamakla birlikte, video kaydı kullanılarak öğrencilerin eksik ve hatalı uygulamalarııı görmesi ve düzeltmesi açııından CPR eğitimine katkı sağlayabileceği öngörülmektedir.

Anahtar sözcükler: (PR, hemşirelik öğrencisi, video kayit

\section{EXAMINATION OF TWO DIFFERENT ASSESSMENT METHODS USED IN CARDIOPULMONARY RESUSCITATION TRAINING}

\section{ABSTRACT}

Aim: This study aims to examine the impact of two different assessment methods used in cardiopulmonary resuscitation (CPR) training.

Materials and Methods: The semi-experimental study was conducted with nursing students taking first-aid lessons in the 2014-2015 academic year at a university. All the participants agreed to the study. Data were collected by the Socio-Demographic Characteristics Questionnaire Form and a CPR Skills Assessment Form. The students in the study were separated into two groups and were given firstaid training. Students applied CPR practice in a skills laboratory after the training. The CPR Practice of Group I $(n=35)$ was recorded by a video camera. Then each student observed and assessed themselves using the self-assessment method to obtain the first mean score. At the second stage, the students who watched the video recording repeated the CPR practice and were assessed by the trainer and the second practice score obtained. The CPR practice of students in Group II $(n=35)$ was assessed by the feedback method given by a single trainer and the first practice scores were obtained. At the second stage, the students repeated the CPR practice and the second practice score was obtained. The data were assessed using the SPSS program.

Results: The mean age of the students included in the study was $20.82 \pm 1.28$. Of the participants, $82.9 \%$ were female and $90 \%$ had completed regular high school. As a result of the study, a statistically significant difference was found between the first and second practice scores $(p<0.05)$. No difference was found between the feedback and the self-assessment method during CPR training.

Conclusion: There was no difference between the two different training methods in terms of acquiring CPR skills. It is predicted that video recordings could facilitate students in observing their ineffective CPR practices and correct them.

Keywords: (PR, nursing student, video recording 
K ardiyopulmoner arrest, solunumun ve dolaşımın aniden durmasıdır. Kardiyopulmoner resüsitasyon (CPR) ise spontan kalp atımı, solunum ve beyin fonksiyonlarının geri dönmesi için yapılan müdahaledir $(1,2)$. CPR' da hedef insanı hayatta tutmaktır. Son derece önemli olan bu duruma müdahalenin en iyi şekilde yapılması, yöntemlerin doğru zamanda, doğru sırada ve gereken biçimde uygulanması, uygulama sırasında eksik ve hata olmaması son derece önemlidir. Uygulamaların etkinliklerinin değerlendirilmesi için yapılan çalışmalar sonucunda resüsitasyon kılavuzları oluşturulmuş ve uygulamalar standardize edilmeye çalışılmıştır (3). Kardiyopulmoner arrest sonrası kişinin yaşama dönmesi için Temel Yaşam Desteği (TYD)'nin en kısa zamanda yapılması gerekmektedir. Kardiyak arrest durumlarında olaya tanık olan kişilerin doğru ve etkili temel yaşam desteği uygulamalarının, hastanın sağ kalımına önemli katkı sağladığı bildirilmiştir (4). TYD eğitimi alan bireyler, derslerden hemen sonra TYD'ni yeterli bir şekilde uygulayabilmektedir. Eğitim sonrası geçen zaman içerisinde TYD becerisinde gerileme başlamaktadır (5). TYD becerilerindeki gerilemenin; bireye ait faktörlere, eğitim müfredatına ve eğiticilerin standart eğitim uygulamamalarından kaynaklandığı belirtilmektedir. TYD becerilerindeki gerilemenin daha az olması için; TYD eğitim süresinin daha uzun olması, eğitim sırasında uygulamanın maketle yapılması ve eğitim esnasındaki yanlış uygulamaların eğitmen tarafından geribildirim yöntemi ile düzeltilmesi önerilmektedir (6). Geribildirim yönteminin eğitimde önemli bir yeri bulunduğu ortaya konmuş bir gerçektir. Farklı türdeki geribildirimlerin değişik yaş gruplarındaki öğrencilerin belli davranışı öğrenmeleri üzerine etkisi bulunmaktadır (7).

Hemşirelik eğitiminde son yıllarda giderek artan bir önem kazanan simülasyon; gerçekçi bir klinik ortamda bilişsel, duyuşsal ve beceri eğitimini; hasta güvenliğini ve etik ilkeleri benimseyerek beceri kazandırmayı amaçlamaktadır $(8,9)$. Beceri kazandırma eğitiminde önemli bir yeri olan video kaydı yöntemi, öğrencinin kendine olan güvenini geliştirmede, fiziksel değerlendirmeyi ve belirli becerileri geliştirmede öğrencilere yardım eden bir öğrenim stratejisidir. Bu yöntemle öğrencinin yaptığı hataları görerek düzeltmesi hedeflenmektedir. Video kaydı kullanma, performansı düzeltme ve süreci değerlendirmede öğrenci ve eğiticiye geri bildirim sağlamaktadır $(10,11)$. Sağlık kurumlarında hasta ile en fazla zaman geçiren meslek grubu hemşirelerdir ve hastane ortamında solunumu ve kalbi duran hastaya ilk müdahalede bulunan kişilerdir. Bu nedenle hemşirelerin meslek hayatına girmeden önce etkili bir CPR eğitimi almaları gerekmektedir (2). Tüm bunlardan yola çıkılarak, bu çalışma CPR eğitiminde kullanılan iki farklı değerlendirme yönteminin öğrenme sürecine etkisini değerlendirmek amacıyla planlanmıştır.

\section{Gereç ve yöntem}

İki grup içeren ve yarı-deneysel türde planlanan bu çalışma, 2015-2016 akademik yılında bir devlet üniversitesinin hemşirelik bölümünde ilk yardım dersine kayıt yaptıran 70 gönüllü öğrenci katılımıyla gerçekleştirilmiştir. Çalışmanın yürütülebilmesi için klinik dışı araştırmalar etik kurulundan ve araştırmaya katılan öğrencilerden yazılı izin alınmıştır. Her iki gruptaki öğrencilere tek bir eğitmen tarafından 2 saatlik sözel anlatım, konu ile ilgili resimler ve maket üzerinde uygulamaları gösteren klasik eğitim ilk yardım eğitimi verilmiştir. Eğitim materyali olarak bilgisayar, projektör ve ilgili CPR konusundaki Avrupa Resüsitasyon Konseyi 2010 (ERC 2010) kılavuzu dökümantasyon olarak kullanılmıştır (12). Eğitimden bir gün sonra öğrenciler sınıf listesine göre gruplandırılıp, numaraları tek olan öğrenciler (35 öğrenci) Grup I, numaraları çift olan öğrenciler (35 öğrenci) Grup II olarak belirlenmiştir. Öğrenciler arasındaki etkileşimi önlemek için her bir öğrenci uygulama salonuna tek tek alınmıştır Uygulama ortalama 8-10 dakika sürmüştür. Bu çalışmada her iki gruptaki öğrenciler için Sosyo-Demografik Özellikler Soru Formu (10 soru) ve ERC tarafından oluşturulan 21 maddelik CPR Beceri Listesi kullanılmıştır.

Grup I öğrencilerinden CPR uygulamasını yaparken öğrencilerin CPR uygulaması video cihazı ile kayıt edilmiştir. Daha sonra, CPR beceri listesi verilerek öğrencilerin kendi video kayıtlarını izleyip, CPR beceri listesindeki doğru uygulamalarının yanına (+) geliştirilmesi gereken basamakların yanına da (-) koyması istenmiştir. Öğrencilerin doğru uygulamalarına bir (1) puan, geliştirilmesi gereken uygulama basamaklarına da sıfır (0) puan verilerek ilk uygulama puanları elde edilmiştir. Bir sonraki aşamada öğrencilerden uygulamayı tekrar etmesi istenmiş ve aynı beceri listesi kullanılarak öğrencilerin ikinci CPR uygulaması bu kez tek bir eğitmen tarafından değerlendirilerek ve ikinci uygulama puanları belirlenmiştir.

Grup II öğrencilerinden CPR uygulamasını gerçekleştirmeleri istenmiştir. Bu aşamada, öğrencilerin performansı CPR beceri listesi kullanılarak tek bir eğitmen tarafından değerlendirilmiştir. Doğru gerçekleştirilen adımlara bir (1) puan ve geliştirilmesi gereken adımlara sıfır (0) puan verilerek ilk uygulama puanı elde edilmiştir. Öğrencilere doğru gerçekleştirdikleri adımlar ve geliştirilmeye ihtiyaCı olduğu adımlar hakkında geri bildirim verilmiştir. Daha sonra, öğrencilerden uygulamayı tekrarlaması istenmiştir. Bu öğrencilerin ikinci CPR uygulaması tekrar araştırmacılar 
tarafından değerlendirilmiş ve ikinci uygulama puanı belirlenmiştir. Tüm CPR uygulamaları Ambu Cardiyak Care CPR yetişkin mankeni üzerinde gerçekleştirilmiştir. Her iki gruptaki öğrencilerin CPR uygulamaları sırasında yeterli ve etkin göğüs basısı yapma durumu ve etkili kurtarıcı nefes verme durumu maket tarafından otomatik olarak kayıt altına alınmıştır. Her iki grupta da öğrencilerin yanlış/yetersiz olan becerileri, öğrenciler doğru uygulama yapana kadar tekrar edilmiştir. Verilerin analizi SPSS-18.0 istatistik programında sayı, yüzde, t-test ve ki-kare ile analiz edilmiştir. Anlamlılık düzeyi $\mathrm{p}<0.05$ olarak kabul edilmiştir.

\section{Bulgular}

Çalışmaya dahil edilen öğrencilerin yaşları 19 ile 25 arasında olup, yaş ortalamasının $20.82 \pm 1.28$ olduğu saptanmıştır. Öğrencilerin \%82.9'unun kadın, \%90'nının düz liseden mezun olduğu saptanmıştır. Çalışmaya dahil edilen öğrencilerin sosyo-demografik özellikleri Tablo 1'de yer almaktadır. Yapılan istatistiksel değerlendirmeye göre öğrencilerin cinsiyet, mezun olunan lise, çalışma durumu, CPR eğitimi almış olma durumu ve sürücü belgesine sahip olma durumu açısından gruplar arasında anlamlı bir fark bulunmamıştır ( $p>0.05)$.

Tablo 2'de Grup I ve Grup II öğrencilerinin ilk ve ikinci uygulama puanlarının ortalamasının karşılaştırııması yer almaktadır. Grup I' deki öğrencilerin ilk uygulama puan ortalaması $18.54 \pm 1.93$, ikinci uygulama puan ortalaması $19.57 \pm 1.24$ 'dir. Grup l'deki öğrencilerin ilk uygulama

Tablo 1. Öğrencilerin Sosyo-demografik özelliklerine göre dağı̆ımı

\begin{tabular}{|c|c|c|c|c|c|c|c|c|}
\hline & & rup I & & |p II & & lam & & \\
\hline $\begin{array}{l}\text { Sosyo-demografik } \\
\text { özellikler }\end{array}$ & $n$ & $\%$ & $n$ & $\%$ & $n$ & $\%$ & $p$ & $X^{2}$ \\
\hline $\begin{array}{l}\text { Cinsiyet } \\
\text { Kadın } \\
\text { Erkek }\end{array}$ & $\begin{array}{c}29 \\
6\end{array}$ & $\begin{array}{l}82.9 \\
17.1\end{array}$ & $\begin{array}{c}29 \\
6\end{array}$ & $\begin{array}{l}82.9 \\
17.1\end{array}$ & $\begin{array}{l}58 \\
12\end{array}$ & $\begin{array}{l}82.9 \\
17.1\end{array}$ & 0.316 & 61.007 \\
\hline $\begin{array}{l}\text { Mezun Olunan Lise } \\
\text { Meslek Lisesi } \\
\text { Düz Lise }\end{array}$ & $\begin{array}{c}4 \\
31\end{array}$ & $\begin{array}{l}11.4 \\
88.6\end{array}$ & $\begin{array}{c}3 \\
32\end{array}$ & $\begin{array}{c}8.6 \\
91.4\end{array}$ & $\begin{array}{c}7 \\
63\end{array}$ & $\begin{array}{l}10 \\
90\end{array}$ & 0.462 & 0.541 \\
\hline $\begin{array}{l}\text { Çalışma Durumu } \\
\text { Hemşire Olarak Çalışan } \\
\text { Çalışmayan }\end{array}$ & $\begin{array}{c}1 \\
34\end{array}$ & $\begin{array}{c}2.9 \\
97.1\end{array}$ & $\begin{array}{c}1 \\
34\end{array}$ & $\begin{array}{c}2.9 \\
97.1\end{array}$ & $\begin{array}{c}2 \\
68\end{array}$ & $\begin{array}{c}2.9 \\
97.1\end{array}$ & 0.147 & 72.103 \\
\hline $\begin{array}{l}\text { CPR Eğitimi Almış } \\
\text { Olma Durumu } \\
\text { Evet } \\
\text { Hayır }\end{array}$ & $\begin{array}{c}4 \\
31\end{array}$ & $\begin{array}{l}11.4 \\
88.6\end{array}$ & $\begin{array}{c}5 \\
30\end{array}$ & $\begin{array}{l}14.3 \\
85.7\end{array}$ & $\begin{array}{c}9 \\
61\end{array}$ & $\begin{array}{l}12.9 \\
87.1\end{array}$ & 0.645 & 0.213 \\
\hline $\begin{array}{l}\text { Sürücü Belgesine } \\
\text { Sahip OIma Durumu } \\
\text { Evet } \\
\text { Hayır }\end{array}$ & $\begin{array}{c}5 \\
30\end{array}$ & $\begin{array}{l}14.3 \\
85.7\end{array}$ & $\begin{array}{c}9 \\
26\end{array}$ & $\begin{array}{l}25.7 \\
74.3\end{array}$ & $\begin{array}{l}14 \\
56\end{array}$ & $\begin{array}{l}20.0 \\
80.0\end{array}$ & 0.194 & 41.690 \\
\hline
\end{tabular}

puan ortalamaları ile ikinci uygulama puan ortalamala$\mathrm{rı}$ arasında istatistiksel olarak anlamlı fark saptanmıştır ( $\mathrm{t}=-4.402, \mathrm{p}=0.000<0.05$ ). Grup Il'deki öğrencilerin ilk uygulama puan ortalaması $18.45 \pm 2.16$, ikinci uygulama puan ortalamaları 19.65 \pm 1.28 'dir. Grup II'deki öğrencilerin ilk uygulama puan ortalamaları ile ikinci uygulama puan ortalamaları arasında istatistiksel olarak anlamlı bir fark saptanmıştır ( $t=-4.825, p=0.000<0.05)$. Grup I ve Grup II' deki öğrencilerinin ikinci uygulama puan ortalamaları ilk uygulama puan ortalamalarına göre anlamlı derecede yüksek bulunmuştur.

Tablo 3' de öğrencilerin ilk ve ikinci uygulama puan ortalamaları arasındaki farkın karşılaştıııması görülmektedir. Illk uygulama puanları ve ikinci uygulama puanları bakımından gruplar arasında istatistiksel olarak anlamlı bir fark bulunmamıştır ( $p>0.05$ ). Bununla birlikte grupların uygulamaları arasındaki farkın da istatistiksel olarak anlamlı olmadığı görülmüştür ( $t=-0.783, p=0.439>0.05)$.

Çalışmaya katılan tüm öğrencilerin ilk uygulamalarında "CPR Beceri Listesi" doğrultusunda unuttuğu ya da hatalı uyguladıkları basamaklar sırasıyla;

- Soluk alıp vermiyorsa, alnının üzerine konulan elin baş ve işaret parmağını kullanarak hasta/yaralının burnunu kapatma (31.4\%),

- Diğer elini bu elin üzerine yerleştirme (28.6 \%)

- Kendisinin ve hasta/yaralının güvenliğinden emin olma (27.1\%)

Tablo 2. Grup I ve Grup II öğrencilerin ilk ve ikinci uygulama puan ortalamalarının karşılaştırıması

\begin{tabular}{ccccc} 
& $\begin{array}{c}\text { Ilk Uygulama Puan } \\
\text { Ortalaması } \\
\boldsymbol{X} \pm \text { Sd }\end{array}$ & $\begin{array}{c}\text { Ikinci Uygulama } \\
\text { Puan Ortalaması } \\
\boldsymbol{X} \mathbf{S d}\end{array}$ & $\boldsymbol{t}$ & $\boldsymbol{p}$ \\
\hline Grup I & $18.54 \pm 1.93$ & $19.57 \pm 1.24$ & -4.402 & 0.000 \\
Grup II & $18.45 \pm 2.16$ & $19.65 \pm 1.28$ & -4.825 & 0.000
\end{tabular}

Tablo 3. Grup I ve Grup II öğrencilerinin ilk ve ikinci uygulama puan ortalamaları arasındaki farkın karşılaştırıması

\begin{tabular}{lcccc} 
& $\begin{array}{c}\text { GRUP I } \\
\text { Puan Ortalamas } \\
\boldsymbol{X} \pm \text { Sd }\end{array}$ & $\begin{array}{c}\text { GRUP II } \\
\text { Puan OrtalamasI } \\
\boldsymbol{X} \pm \mathbf{S d}\end{array}$ & t & $\boldsymbol{p}$ \\
\hline İlk Uygulama & $18.54 \pm 1.93$ & $18.45 \pm 2.16$ & 0.620 & 0.539 \\
İkinci Uygulama & $19.57 \pm 1.24$ & $19.65 \pm 1.28$ & -0.452 & 0.654 \\
Uygulamalar & & & & \\
Arası Fark & $1.02 \pm 1.38$ & $1.20 \pm 1.47$ & -0.783 & 0.439
\end{tabular}


- Hasta/yaralının kravat, kemer ve yakasını açma (25.7\%) şeklindedir (Tablo 4).

Tablo 4. Öğrencilerin ilk uygulamalarının "CPR beceri listesi"

basamaklarına göre dağlımı

\section{CPR Beceri Listesi Basamakları \\ CPR Beceri Listesi Basamakları}

\begin{tabular}{ccccc} 
Doğru & \multicolumn{2}{c}{ Yanlış } \\
\hline$n$ & $\%$ & $n$ & $\%$
\end{tabular}

1. Kendisinin ve hasta/yaralının güvenliğinden

$\begin{array}{llll}51 & 72.9 & 19 & 27.1\end{array}$ emin olma

2. Hasta/yaralının omuzlarına hafifçe dokunarak ve $\begin{array}{lllll}66 & 94.3 & 4 & 5.7\end{array}$ "iyi misiniz?" diye sorarak bilincini kontrol etme eğer bilinci yok ise:

3. Tıbbi yardım isteme (112 arama)

$\begin{array}{llll}69 & 98.6 & 1 & 1.4\end{array}$

4. Hasta/yaralıyı sert bir zemin üzerine yatırma

5. Hasta/yaralının yanına diz çökmek

$\begin{array}{llll}70 & 100 & 0 & 0\end{array}$

6. Hasta/yaralının kravat, kemer ve yakasını açma

$\begin{array}{llll}64 & 91.4 & 6 & 8,6\end{array}$

7. Ağız içini kontrol ederek hava yolu tıkanıklığına neden olan cisim varsa çıkarma

8. Hava yolunu açmak için bir elini hasta/yaralının $\begin{array}{lllll}62 & 88.6 & 8 & 11.4\end{array}$ alnına, diğer elinin parmak uçlarını çenesinin altına yerleştirme

9. Çene kemiğinin uzun kenarı yere dik gelecek şekilde başı geriye doğru eğme

10. Hasta/yaralının solunum yapıp yapmadığını bak-dinle-hisset yöntemiyle 10 saniye süre ile kontrol etme

11. Soluk alıp vermiyorsa, alnının üzerine konulan elin baş ve işaret parmağını kullanarak

hasta/yaralının burnunu kapatma

12. Baş geriye doğru eğilmiş pozisyonda iken hasta/ yaralının ağzını içine alacak şekilde yerleştirme

13. Eğer solunum yoksa Hasta/yaralının göğsünü yükseltmeye yarayacak kadar her biri bir saniyenin üzerinde 2 kurtarıcı nefes verme, havanın geriye çıkıp çıkmadığını kontrol etme

14. Kalp basısı uygulamak için göğüs kemiğini ortalayarak (göğüs kemiğinin üst ve alt ucunun ortası) göğüsün merkezini tespit etme

15. Bir elin topuğunu göğsün merkezine yerleştirme $\begin{array}{lllll}53 & 75.7 & 17 & 24.3\end{array}$

16. Diğer elini bu elin üzerine yerleştirme $\begin{array}{llll}50 & 71.4 & 20 & 28.6\end{array}$

17. Her iki elin parmaklarını biri birine geçirme

18. Parmakları göğüs kafesi ile temas ettirmeden, dirsekleri bükmeden, göğüs kemiği üzerine vücuda dik olacak şekilde tutma

19. Göğüs kemiği $4-5 \mathrm{~cm}$ aşağı inecek şekilde (yandan bakıldığında göğüs yüksekliğinin 1/3'ü kadar) bası uygulama, bu işlemi dakikada 100 kez uygulama

20. Hasta/yaralıya 30 kalp masajindan sonra 2 solunum yaptırma $(30: 2)$

21. Temel yaşam desteğine hasta/yaralının yaşamsal refleksleri veya tıbbi yardım gelene kadar kesintisiz devam etme

\section{Tartışma}

Çalışmaya dahil edilen öğrencilerin \%12.9 CPR eğitimini daha önce aldıklarını bildirmişlerdir. Demir Korkmaz ve ark. (2016)'nın hemşirelik öğrencileri ile yapmış oldukları çalışmada \%14.5'inin daha önce CPR eğitimi aldıkları (10); Kardong ve ark. (2010) ise öğrencilerin \%91.9'unun CPR konusunda önceden eğitim almış oldukları (13) belirtilmiştir. Bu çalışmada hemşirelik öğrencilerinin hemşirelik programına girmeden önce ya da klinik deneyimlerine başlamadan önce CPR dersini başarılı bir şekilde tamamlamaları gerektiği belirtilmektedir (13). Çalışmamızda CPR eğitimini daha önce almış olma durumu, öğrencilerin sağlık meslek lisesi hemşirelik bölümünde eğitim almalarından ve sürücü belgesine sahip olma durumundan kaynaklanmaktadır. Çalışmaya dahil edilen 2 öğrencinin hemşire olarak çalıştığı belirlenmiştir. Avrupa Resüsitasyon Konseyi kılavuzunda TYD bilgi ve becerilerine sahip olmayı tüm sağlık çalışanlarının görevi olarak bildirmiştir. Ülkemizdeki bütün hemşirelik okullarının hemşirelik bölümü eğitim müfredatında yer alan ilk yardım dersi ile TYD eğitimi verilmektedir. Çalışmaya dahil edilen öğrencilerin beşte birinin sürücü belgesinin olduğu saptanmıştır. Ancak sürücü belgesine sahip olma ile CPR beceri puan ortalaması arasında istatistiksel olarak anlamlı bir ilişki bulunmamıştır. Ülkemizde sürücü belgesi alabilmek için 18 yaşını doldurmuş olmak ve eğitim sırasında 12 saatlik ilk yardım dersi almak gerekmektedir. Araştırma kapsamına alınan öğrencilerin yaş ortalamasının $20.82 \pm 1.28$ olduğu göz önüne alınırsa, öğrencilerin son 2-3 yıl içerisinde ilk yardım eğitimi aldığı ve dolayısıyla sürücü belgesine sahip öğrencilerin CPR becerisi puan ortalamalarının daha yüksek olması beklenirdi. Bu durum eğitim sonrası geçen zaman içerisinde CPR becerisinde gerileme başladığını göstermektedir (5).

Literatürde TYD eğitiminde ve bilgilerin unutulmamasında en önemli faktörün eğitim sırasında uygulamanın simülatör maketle yapılması ve eğitim esnasındaki yanlış uygulamaların eğitmen tarafından düzeltilmesi önerilmektedir $(14,15)$. Simülasyon temelli resüsitasyon eğitiminin hemşirelerin bilgi, performans ve öz-yeterliliğini geliştirdiğini göstermiştir $(16,17)$. Çalışmaya dahil edilen öğrencilerin uygulamalarını maket üzerinde yapılması sağlanmış, Grup I ve Grup II' deki öğrencilere yapmış oldukları hatalı uygulamalar için geribildirim verilmiştir. Hatalı uygulamalar için verilen geribildirimin öğrencilerin uygulama puanı üzerine etkisi olduğu görülmüştür. Grup I ve Grup II öğrencilerinin ikinci uygulama puan ortalamaları, birinci uygulama puan ortalamalarına göre anlamlı derecede yüksek olarak saptanmıştır. Bu çalışmanın sonucunda hemşirelik 
öğrencilerinin CPR eğitiminde kullanılan iki farklı değerlendirme yönteminin de öğrenme sürecine eşit düzeyde etkili olduğu bulunmuştur. CPR becerilerinin uygulanmasında kendi kendine değerlendirme yöntemi ile öğretim elemanı tarafından değerlendirme yöntemi arasında CPR becerisinin öğrenilmesi açısından fark olmadığı saptanmıştır. Demir Korkmaz ve ark. (2016)'nın yapmış oldukları çalışmada, CPR becerilerinin uygulanmasında kendine kendine değerlendirme yöntemi ile öğretim elemanı tarafından değerlendirme yöntemi arasında CPR becerisinin öğrenilmesi açısından fark saptamamışlardır (10). Bizim çalışmamızda aynı sonuçları içermektedir. Video kaydında kendilerini değerlendiren öğrenci grubu, bu durumun kendilerini değerlendirmede etkili bir yöntem olduğunu sözel olarak belirtmişlerdir.

Temel Yaşam Desteği uygulamalarındaki başarı, verilen eğitimlerin güncellenmiş bilgilerle donatılarak yeterli pratiklerin yaptırılması ve verilecek eğitimlerin yaygınlaştırılması ile sağlanabilmektedir. Mağdurları hayatta tutacak olan müdahaleler belirli periyodlarda yayınlanan kılavuzlarda ayrıntılı şekilde anlatılmaktadır. Hem kurtarıcının hem de mağdurun hayatını tehlikeye atmamak için kılavuzlarda belirtilen ilk şey, ilk yardımcının kendisinin ve hasta/yaralının güvenliğinin sağlanmasıdır $(10,12)$. Kımaz ve ark.(2006) yaptıkları çalışmada, katılımcıların \%66'sının (18); Demir Korkmaz ve ark. (2016) yaptıkları çalışmada katılımcıların \%94.7'sini ilk olarak çevre güvenliğini sağladığını tespit etmişlerdir (10). Çalışmaya dahil edilen öğrencilerin $\% 72.9^{\prime} u$ kendisinin ve hasta/yaralının güvenliğini sağlama basamağını doğru olarak gerçekleştirmişlerdir.

\section{Kaynaklar}

1. Canpolat DG, Gönen ZB, Doğruel F, Şengül I, Yıldız K. Diş Hekimlerinin Kardiyopulmoner Resüsitasyon Bilgi Düzeylerinin Belirlenmesi. Gaziantep Med J 2016;22:197-201. [CrossRef]

2. Kara F, Yurdakul A, Erdoğan B, Polat K. Bir Devlet Hastanesinde Görev Yapan Hemşirelein Güncel Temel Yaşam Desteği Bilgilerinin Değerlendirilmesi. MAKÜ Sağ Bil Enst Derg 2015;3:17-26. Erişim: https://dergipark.org.tr/download/article-file/181588

3. Uyanık A. Temel Yaşam Desteği Kursunda Video Eğitimi Ille Geleneksel Eğitimin Öğrenme Becerileri Üzerine Ekilerinin Karşılaştırılması. Pamukkale Üniversitesi Tıp Fakültesi Acil Tıp Anabilim Dalı Uzmanlık Tezi; 2013.

4. Kayıpmaz AE, Akpınar C, Altıparmak N, Kavalcı C, Gedik HG, Aydoğdu $C$, et al. Cardiopulmonary Resuscitation Training Improves The Quality Of Basic Life Support Provided By Untrained Rescuers With Dispatcher Guidance. Kırıkkale Üniv Tıp Fak Derg 2017;19:55-9. [CrossRef]

5. Türkmen E, Işık I, Balcı S, Akkuş Topçu S, Abalı S, Karaçay P. Temel Yaşam Desteği Kursuna Katılan Hemşirelik/Sağlık Yüksekokulu Öğrencilerinin Kurstaki Başarı, Beklenti ve Memnuniyetleri. Yoğun Bakım Hem Derg 2009;13:55-62. Erişim: https://dergipark.org.tr/ download/article-file/260120
Bu oranın Demir Korkmaz ve ark. (2016) yapmış olduğu çalışmaya göre çok düşük, Kımaz ve ark.(2006)'nın çaIışmasına oranla yüksek olduğunu saptanmıştır $(10,18)$. Çalışmada öğrenciler tarafından CPR uygulaması sırasında unutulan veya hatalı uygulanan basamaklar; soluk alıp vermiyorsa, alnının üzerine konulan elin baş ve işaret parmağını kullanarak hasta/yaralının burnunu kapatma, diğer elini bu elin üzerine yerleştirme, kendisinin ve hasta/yaralının güvenliğinden emin olma ve hasta/yaralının kravat, kemer ve yakasını açmadır. Uyanık (2013) yaptığı çalışmada, eğitim maketine baş-çene pozisyonu verilerek hava yolu açıklığının uygun şekilde sağlanıp burun kanatları kapatıldıktan sonra doğru bir şekilde ağızdan ağıza soluk verme işleminin doğru yapılma oranı video grubunda \%89,1 ve klasik grupta \%91,7 olarak saptanmıştır. Aynı çalışmada katılımcının kendisi ve mağdur için güvenli bir alan oluşturup oluşturmamasına en fazla doğru cevabı klasik grup verirken; katılımcıların eğitim maketinin sıkan giysilerini video grubunun $\% 60,9^{\prime} \mathrm{u}$, klasik grubun $\% 70,8^{\prime} \mathrm{i}$ gevşettiği bulunmuştur (3).

Sonuç olarak, CPR becerilerinin uygulanmasında kendi kendine değerlendirme yöntemi ile öğretim elemanı tarafından değerlendirme yöntemi arasında CPR becerisinin öğrenilmesi açısından fark bulunmamakla birlikte, video kaydı kullanılarak öğrencilerin eksik ve hatalı uygulamalarını görmesi ve düzeltmesi açısından CPR eğitimine katkı sağlayabileceği öngörülmektedir. Her iki değerlendirme yönteminden kendi kendine değerlendirme yönteminin CPR becerisinin öğretilmesinde etkili bir yöntem olarak kullanılması önerilmektedir.

6. Soysal S, Karcıoğlu Ö, Korkmaz T, Topaçoğlu H. Temel Yaşam Desteği Eğitimi İdeal Ne Kadar Uzakta? Akademik Acil Tıp Derg 2005;:40-6. Erişim: http://www.journalagent.com/atuder/pdfs/ ATUDER_3_5_40_46.pdf

7. Çalışkan M. Etkili Dönüt Verme Yolları. Turkish Studies 2015;10/11:417-30. [CrossRef]

8. Durmaz Edeer A, Dicle A. Hemşirelik Eğitiminde Simülasyon Kullanımı ve Simülasyon Tipleri. HEAD 2015;12:121-5. [CrossRef]

9. Gürol A, Balcı Akpınar R, Ejder Apay S. Simulasyon Uygulamalarının Öğrencilerin Beceri Düzeylerine Etkisi. Kocatepe Tıp Derg 2016;17:99104. Erişim: https://dergipark.org.tr/download/article-file/210814

10. Demir KorkmazF, Ozsaker E, Tasdemir N, Karacabay K. An Examination of the Effect Two Different Evaluation Methods Used in CPR Training Have on the Learning Process. Croatian J Educ 2016;18:157-75.

11. Alkhalaileh M, Hasan AA, Al-Rawajfah O. Evaluate the Effectiveness of Clinical Simulation and Instructional Video Training on the Nursing Students' Knowledge about Cardio-Pulmonary Resuscitation: Comparative Study. Am J Educ Res 2017;5:172-8. [CrossRef]

12. Nolana JP, Soar J, Zideman DA, Biarent D, Bossaert LL, Deakin C, et al. European Resuscitation Council Guidelines for Resuscitation 2010 Section 1. Executive summary. Resuscitation 2010;81:1219-76. [CrossRef] 
13. Kardong-Edgren S, Oermann M. H, Odom-Maryon T, Ha Y. Comparison of two instructional modalities for nursing student CPR skill acquisition. Resuscitation 2010;81:1019-24. [CrossRef]

14. Uysal H. Kardiyak Arrest ve Hemşirelik Bakımı. Türk Kardiyol Dern Kardiyovask Hem Derg 2010;1:19-27. [CrossRef]

15. Kardong-Edgren S, Adamson KA. BSN Medical-Surgical Student Ability to Perform CPR in a Simulation: Recommendation and Implications. Clin Simul Nurs 2009;5:e79-83. [CrossRef]

16. Taş D, Akyol A. Kardiyopulmoner Resüsitasyon Eğitiminde Yeni Eğilim: Yüksek-Güvenirlikli Simulasyon. Turk J Card Nur 2017;8:1008. [CrossRef]
17. Richardson KJ, Claman F. High-fidelity simulation in nursing education: A change in clinical practice. Nurs Educ Perspect 2014;35:125-7. [CrossRef]

18. Kımaz S, Soysal S, Çımrın AH, Günay T. 112 Acil Sağlık Hizmetlerinde Görevli Doktorların Temel Yaşam Desteği, İleri Kardiyak Yaşam Desteği Ve Doktorun Adli Sorumlulukları Konularındaki Bilgi Düzeylerinin Değerlendirilmesi. Ulus Travma Derg 2006;12:59-67. 